\title{
CCND1 Negative
}

National Cancer Institute

\section{Source}

National Cancer Institute. CCND1 Negative. NCI Thesaurus. Code C147089.

Indicates that expression of CCND1 has not been detected in a sample. 